\title{
A Model of Adolescent Sleep Health and Risk for Type 2 Diabetes
}

\author{
Stacey L. Simon ${ }^{1} \cdot$ Janine Higgins ${ }^{1} \cdot$ Edward Melanson ${ }^{1,2} \cdot$ Kenneth P. Wright $\mathrm{Jr}^{1,3} \cdot$ Kristen J. Nadeau $^{1}$
}

Accepted: 18 December 2020 / Published online: 15 January 2021

(C) The Author(s), under exclusive licence to Springer Science+Business Media, LLC part of Springer Nature 2021

\begin{abstract}
Purpose of Review This paper presents a review of the current literature in support of a model explaining the relationships between sleep health and risk for type 2 diabetes in adolescents.

Recent Findings Short sleep duration is associated with risk of developing obesity in youth. Sleep restriction increases energy expenditure, but also increases hunger, appetite, and food intake, causing positive energy balance, impacting appetite-regulating hormones, and leading to increased eating late at night. Insufficient sleep may lead to reduced physical activity and greater sedentary behaviors. In addition, short sleep duration is associated with reduced insulin sensitivity. The cumulative negative consequences of insufficient sleep increase risk for type 2 diabetes. Applications to clinical care, public policy, and future research are discussed.

Summary Insufficient sleep in adolescence increases risk for type 2 diabetes directly through impact on insulin sensitivity and indirectly through increased dietary intake, sedentary activity, and weight gain.
\end{abstract}

Keywords Insufficient sleep $\cdot$ Pediatrics $\cdot$ Glucose metabolism $\cdot$ Insulin resistance

\section{Introduction}

An overwhelming majority (78\%) of high school-age adolescents report sleeping less than the recommended $8-10 \mathrm{~h}$ per night $[1,2]$. Simultaneously, rates of type 2 diabetes (T2D) are

\begin{tabular}{l}
\hline Kenneth P. Wright Jr. and Kristen J. Nadeau are co-senior authors \\
\hline This article is part of the Topical Collection on Psychosocial Aspects \\
\hline Stacey L. Simon \\
Stacey.Simon@ childrenscolorado.org \\
Janine Higgins \\
Janine.Higgins@ cuanschutz.edu \\
Edward Melanson \\
Ed.Melanson@cuanschutz.edu \\
Kenneth P. Wright, Jr \\
Kenneth.Wright@ colorado.edu \\
Kristen J. Nadeau \\
Kristen.Nadeau@childrenscolorado.org \\
1 University of Colorado Anschutz Medical Campus, Aurora, CO, \\
USA \\
Eastern Colorado Veterans Affairs Geriatric Research, Education, \\
and Clinical Center, Denver, CO, USA \\
University of Colorado Boulder, Boulder, CO, USA
\end{tabular}

increasing among youth [3]. One contributor to insufficient sleep is the physiological shift in circadian rhythm that occurs mid-adolescence, causing later sleep onset [4]. When coupled with academic, extra-curricular, and social demands, light exposure from evening electronics use, and imposed early school start times, it is difficult for adolescents to obtain sufficient sleep [4]. Because insufficient sleep is linked to insulin resistance (IR) [5], the high incidence of insufficient sleep in adolescents may be a factor underlying the increasing rates of T2D in youth [3].

IR peaks during puberty, is frequently greater in adolescents with obesity than those of normal weight, and contributes significantly to T2D development and cardiometabolic risk $[6,7]$. T2D presents aggressively in adolescents, with rapid onset of $\beta$ cell failure compared with adults $[3,8]$. Given that obesity currently impacts approximately $1 / 3$ of adolescents in the USA [9], alternative T2D prevention and treatment targets for youth are urgently needed to prevent future morbidity and mortality.

Adults that habitually maintain insufficient sleep schedules demonstrate IR, and findings from laboratory-based studies show that experimentally induced insufficient sleep in adults induces IR [10-15]. For example, 5 days of insufficient sleep led to a $20 \%$ decrease in insulin sensitivity in healthy adults in one study [16], and emerging evidence suggests a similar relationship between insufficient sleep and IR in adolescents 
[5]. Yet, multiple unique developmental and physiological changes occur during adolescence, limiting the generalizability of adult studies to adolescents. Thus, we developed a model to explain the relationship between sleep health and risk for $\mathrm{T} 2 \mathrm{D}$ in adolescents based on the current literature.

\section{Model of Sleep and Risk for Diabetes in Adolescents}

Our model (Fig. 1) posits that the pubertally related circadian delay that leads to a propensity for delayed bedtimes, combined with forced early morning school day rise times, results in insufficient sleep. Insufficient sleep may then lead to decreased physical activity, increased evening food intake, and increased weight gain and obesity risk. Thus, in addition to pubertally induced IR, insufficient sleep both directly and indirectly, through its impact on activity, diet, and weight, results in IR, which in turn, increases future risk for developing T2D. Here, we discuss the evidence base to date in support of this model.

\section{Definition of Sleep Health in Adolescents}

Sleep health is a multidimensional construct, including sleep duration, continuity or efficiency, timing, sleepiness, and subjective satisfaction or quality [17]. For the purpose of the current manuscript, we will focus on sleep duration, while acknowledging the impact and importance of future research in these and other domains, including circadian misalignment, and obstructive sleep apnea, insomnia, and other sleep disorders.

\section{Insufficient Sleep in Adolescents}

Chronic insufficient sleep is endemic in today's adolescents, with typical sleep duration well below recommendations for age $[1,2]$. A pubertal shift in circadian rhythms results in a delayed bedtime, which is compounded by increased academic, extracurricular, and social demands [4]. These factors drive late sleep onset, which, when combined with imposed early school start times, result in high rates of insufficient sleep in

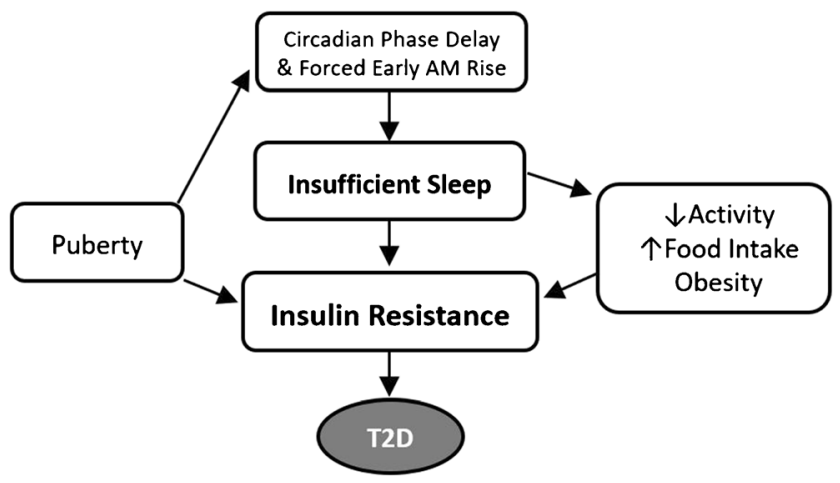

Fig. 1 A model of sleep and risk for diabetes in adolescents adolescents [4]. Data from the 2019 Youth Risk Behavior Survey reveal that $83 \%$ of 12 th grade students report obtaining $<8 \mathrm{~h}$ sleep per night, and as many as $43 \%$ of teens obtain $<6 \mathrm{~h}$ sleep per night [1].

Adolescence is a developmental stage during which youth have more autonomy over their bedtimes, which has been shown to result in later bedtimes and shorter sleep duration [18]. In addition, high rates of screen-based electronics use in adolescents increase evening light exposure, which may further delay circadian rhythms and have been shown to promote later bedtimes and insufficient sleep [18, 19]. Over $70 \%$ of adolescents report using at least one electronic device at least $1 \mathrm{~h}$ before sleep, and $30 \%$ of adolescents use mobile devices throughout the night [19].

Negative consequences of insufficient sleep in adolescents are numerous and include attention difficulties [20], mood and behavior problems, and poor academic performance [21]. As a result, the American Academy of Pediatrics recommends that high schools start no earlier than 8:30 am to provide adolescents with the opportunity to obtain sufficient sleep aligned with their biological clock [22]. Yet, the majority of middle and high schools start much earlier (average start time is 8:03 am), indicating that most youth are at risk for short sleep duration and highlighting that examination of the impact of short sleep on T2D risk is vital.

\section{Sleep Health and Association with Obesity}

The link between sleep and risk of obesity is well established. Correlational data from a meta-analysis of an international sample of 2-20-year-olds suggest that for each hour less sleep obtained, there is a corresponding $80 \%$ increase in obesity risk to youth [23]. In adolescents, ages 10-16 years, each additional hour of sleep obtained was associated with a decrease in BMI percentile by 3.6 points as well as lower body fat[24•]. Longitudinal research affirms these findings: one longitudinal study found that adolescent self-reported sleep problems (e.g., difficulty sleeping, daytime sleepiness) were associated with an increased risk of developing overweight/obesity in young adulthood [25]. Additionally, age and sex may be important factors in this association: in a longitudinal assessment of adolescents biannually at six timepoints, shorter sleep at baseline was found to be associated with an increase in BMI over time for older adolescent females (16-18 years), whereas baseline sleep was associated only with baseline BMI, not weight gain over time, for males [26]. Finally, findings from a meta-analysis of prospective studies revealed a causal relationship between short sleep duration and subsequent weight gain and obesity in youth across development, including adolescence [27•]. Specifically, short sleep duration was associated with a two-fold increased risk of developing obesity in youth [27•]. 


\section{Sleep Health and Association with Dietary Intake}

Findings from laboratory studies in adults show that sleep restriction (4-5 h per night) increases total energy expenditure by $\sim 5 \%$ but also increases hunger, appetite, and food intake, causing positive energy balance $[28 \bullet \bullet, 29]$. It is hypothesized that the function of this additional food intake is to compensate for the additional energy expenditure of increased wakefulness, but intake is excessive when food is readily available [29]. This increased energy intake following insufficient sleep may have implications for obesity and T2D risk [30, 31].

Similar results have been found in studies of adolescents. Adolescents ages 14-16 years consumed 10\% more calories and $110 \%$ more servings of sweet/dessert foods during a week of experimental insufficient sleep ( $6.5 \mathrm{~h}$ time in bed) compared with longer sleep (10 h time in bed) [30, 31]. Additionally, teens rated images of sweets/desserts as more appealing after insufficient sleep than longer sleep, while no difference was found in ratings of hunger or non-sweet foods [31]. Similarly, adolescents performed more poorly on a foodrelated inhibitory control task and had higher food reward following a week of insufficient sleep ( $5 \mathrm{~h}$ time in bed) compared with a week of habitual sleep ( $9 \mathrm{~h}$ time in bed) [32]. These findings suggest that insufficient sleep may impact dietary choices by increasing the reward value of foods, particularly foods that are carbohydrate dense.

Conflicting evidence exists as to whether insufficient sleep may influence levels of appetite-regulating hormones leptin and ghrelin [33]. In adults, increased evening ghrelin was associated with greater energy intake following sleep restriction in laboratory studies [34]. Similarly, a meta-analysis of 21 adult studies found that insufficient sleep duration was associated with increased ghrelin levels [35]. In a study of children 8-11 years of age, however, youth reported lower energy intake and had lower fasting morning leptin levels but no difference in ghrelin was observed following 1 week of increased sleep duration ( $1.5 \mathrm{~h}$ more time in bed compared with typical sleep) compared with a week of decreased sleep (1.5 h less time in bed) [36]. In an experimental study, adolescent boys had no difference in leptin and ghrelin concentrations and actually consumed fewer calories during an ad libitum meal opportunity controlling for dietary intake on previous days following 3 nights of insufficient sleep ( $4 \mathrm{~h}$ time in bed) compared with 3 nights of longer sleep ( $9 \mathrm{~h}$ time in bed) [37]. Thus, data regarding the role of insufficient sleep on appetite-regulating hormones in adolescents are equivocal and research specifically designed to address impacts of insufficient sleep on appetitive hormones rather than as an adjunct to studies with other primary outcomes and using high-quality methods are needed.

Timing of eating in relation to sleep may be another important factor. Adults with later timing of sleep (later bed and wake time) consumed more protein, fat, and carbohydrates in the evening (after $8 \mathrm{pm}$ ), and dietary intake after $8 \mathrm{pm}$ was associated with higher BMI [38]. Evidence suggests that dietary intake during times of high circulating melatonin levels (late at night, or early in the morning) may contribute to weight and metabolic dysregulation $[39,40]$. The consequences of late eating timing have potential negative implications for adolescents, given the circadian phase delay that occurs in this developmental stage, and adolescents, particularly those with late chronotype (diurnal preference), demonstrate most eating occasions clustered late in the day [41, 42]. Indeed, later chronotype was associated with greater evening caloric intake in one sample of adolescents [42]. Moreover, later bedtime was associated with insufficient sleep duration and both decreased intake of fruits and vegetables and increased intake of foods such as pizza, soda, and sweets/ desserts in youth 12-18 years of age [43]. However, specific research in adolescents is needed on the timing of eating in relation to sleep and glucose metabolism or obesity risk.

\section{Sleep Health and Association with Physical Activity}

It has been hypothesized that insufficient sleep duration may reduce adolescent's participation in physical activity, in part due to increased daytime sleepiness and fewer activity opportunities in the evening hours. However, the existing literature is limited both in number of studies and reliance on self-report measures, and findings are mixed. Contrary to this hypothesis, in one study of Saudi adolescents, longer self-reported sleep duration was associated with high screen time and low-tomedium physical activity levels, whereas insufficient sleep was associated with high levels of physical activity [44]. In contrast, several other studies have shown that shorter sleep duration and poor sleep quality were associated with less physical activity, more electronics use, and higher sedentary behaviors in adolescents using both subjective and objective assessments [45-49].

In an experimental study with objectively measured sleep and activity, adolescents increased time spent in sedentary behaviors during 2 weeks of habitual short sleep duration (5-7 h per night) when compared with 2 weeks of sleep extension ( $1.5 \mathrm{~h}$ increased time in bed), with no differences in light or moderate-to-vigorous physical activity [50]. Thus, the authors posited that increasing sleep in short-sleeping adolescents reduces sedentary time without impacting physical activity behaviors, implying that extra wakefulness during insufficient sleep is sedentary time [50]. Similarly, an association between short sleep and sedentary behaviors was consistently observed in a systematic review, but the impact of sleep on physical activity and electronics use was not able to be determined, primarily due to few studies and poor quality of the existing research [33].

The combined health benefit of meeting both sleep and physical activity recommendations has been reported in the 
literature. Accelerometer data from adolescents ages 10 16 years revealed that, compared with those with insufficient sleep and low physical activity, adolescents that met guidelines for adequate sleep duration and physical activity had lower cardiometabolic risk factors and adiposity [51]. A review of studies in which physical activity was objectively measured in youth (ages 5-17 years) found that those with a combination of high physical activity, longer sleep duration, and low sedentary behaviors had lower adiposity and better measures of cardiometabolic health (e.g., waist circumference, HOMA-IR, triglycerides) compared with those with low physical activity, short sleep, and high sedentary time [52]. This suggests that evaluating healthy lifestyle behaviors in combination rather than in isolation may be important.

\section{Sleep Health and Association with Insulin Resistance}

Evidence is mounting that insufficient sleep duration is associated with IR in youth. Self-reported insufficient sleep duration is associated with IR assessed with fasting measures and measures from a hyperglycemic clamp in youth ages 10 19 years [53, 54]. Further, actigraphy-estimated sleep was found to be significantly associated with insulin sensitivity measured with fasting glucose and insulin in adolescents ages 13-19 years, but this relationship was attenuated when weight status was included in the model [55]. This was examined further in another study of youth ages $2-15$ years in which it was found that abdominal adiposity mediated the relationship between insulin sensitivity (HOMA-IR) and self-reported sleep duration [56]. Finally, actigraphy-assessed longer sleep duration and higher sleep efficiency were associated with lower metabolic risk scores, composed of waist circumference, systolic blood pressure, high density lipoprotein cholesterol (HDL-C), triglycerides, and HOMA-IR [57•]. However, each of these studies was limited by either using only fasting glucose and insulin rather than more sensitive assessments of IR or subjective assessment of sleep.

The sleep and IR relationship has been examined in few studies of adolescents using both objectively measured sleep and more sensitive assessment of IR. In a sample of adolescents ages 14-19 years with overweight/obesity during the academic year, shorter actigraphy-estimated sleep duration on weekends and weekdays, as well as later weekday bedtimes, was significantly associated with IR assessed with an oral glucose tolerance test [5]. In a randomized cross-over inlaboratory study design, adolescent boys demonstrated lower HOMA-IR after three nights of insufficient sleep opportunity ( $4 \mathrm{~h}$ time in bed) compared with three nights of longer sleep opportunity ( $9 \mathrm{~h}$ time in bed) [58]. In sum, the extant literature provides evidence that short sleep is associated with IR in adolescents but additional research using both objective measurement of sleep and more rigorous stimulated measures of insulin sensitivity and secretion are needed.

\section{Sleep Health and Risk for Type 2 Diabetes}

The negative metabolic consequences of insufficient sleep increase risk for T2D. In adults, a U-shaped relationship has consistently been found with both short and long sleep associated with risk for developing T2D [59•,60]. An analysis of the pooled related risks of multiple sleep variables found that the diabetes risk conferred by insufficient sleep, as well as other sleep factors such as obstructive sleep apnea, poor sleep quality, and shift work, was comparable with traditional risk factors such as weight, family history, and sedentary activity [61]. Less research has been conducted in adolescents, but a narrative review of the pediatric literature found that there was "compelling evidence" for a link between both objectively and subjectively assessed sleep duration with biomarkers of T2D in youth (e.g., adiposity, glucose homeostasis), even after accounting for weight, pubertal status, age, and sex (though physical activity and dietary intake were not controlled for) [62].

\section{Clinical Applications}

Health care providers working with adolescents, particularly those with obesity or other risk factors for T2D, should consider including assessment and treatment of sleep health in their routine care. Specifically, querying about bed and wake times on both weekdays and weekends and encouraging adolescents to schedule adequate time in bed to allow for enough time to obtain the recommended $8-10 \mathrm{~h}$ of sleep per night are important [2]. Additionally, delayed school start times have been shown to result in increased sleep duration and less variability between weekday and weekend sleep in high school students $[63 \bullet \bullet, 64]$. Thus, policy changes to delay school start times may be beneficial for the metabolic health of adolescents [22].

\section{Future Research}

Extending sleep duration may reverse the negative metabolic consequences of insufficient sleep, though findings are mixed. In habitually short-sleeping young-adult men, three nights of $10 \mathrm{~h}$ in-lab time in bed resulted in improved insulin sensitivity [65] and two nights of in-lab "recovery sleep" (10 h per night) reversed the effect of insufficient sleep on IR [66]. Conversely, 2-5 nights of recovery sleep (9-10 h time in bed or ad libitum sleep opportunity) were not sufficient to improve insulin sensitivity following insufficient sleep in other studies with adults $[16,67,68]$. It may be that improved sleep must be sustained in order to benefit metabolic health: adult participants demonstrated improved insulin sensitivity following 6 weeks of in-home sleep extension [69]. Sleep extension with youth has been shown to be feasible by changing sleep onset times [70,71], and increased sleep was found 
to improve attention, memory, problem-solving, emotional regulation, and depression [71-73]. Thus, research investigating the impact of experimental sleep extension and sleep health intervention specifically on IR in adolescents is warranted. Given that individual school start times are not usually individually modifiable, focusing on sleep onset times may be most feasible.

Beyond sleep duration, variability in sleep timing, or social jetlag, defined as the difference between weekday and weekend sleep times, is another variable worthy of investigation. A social jet lag $>1 \mathrm{~h}$ was reported by $87 \%$ of adolescents in one study, with nearly $60 \%$ of youth endorsing a $>2$-h difference between weekday and weekend sleep times [74]. While studies in adults consistently report that greater social jetlag is associated with metabolic risk factors and diabetes/prediabetes diagnosis $[75,76]$, findings are mixed on the impact of social jetlag and diabetes risk factors in adolescents. One study found an increase in adiposity corresponding to each additional hour of social jetlag in adolescent girls, but not boys [77]. Another study found that social jetlag was associated with lower odds of healthy dietary behaviors (e.g., breakfast consumption, fruit and vegetable intake, and fast food consumption, and higher BMI in a study of over 3000 adolescents) [78]. Conversely, social jetlag was associated with healthier lifestyle behaviors (physical activity and dietary intake) and lower BMI in two other studies of youth [74, 79]. Given the high prevalence, additional research clarifying the impact of social jetlag on metabolic risk factors in adolescents is needed.

Circadian misalignment is another factor that must be examined in future research. Circadian rhythms are near-24-h patterns of behavior and physiology regulated by the suprachiasmatic nucleus of the hypothalamus and synchronized by light/dark changes [80]. Evidence suggests that circadian misalignment is associated with IR in adults $[16,81]$. Compared with adults and younger children, however, adolescents demonstrate a pubertally-related delay in melatonin secretion and the forced early rise times common for high school students results in adolescents being awake at inappropriate circadian times [82]. Indeed, morning circadian misalignment, or wakefulness while melatonin levels remained elevated, was associated with IR (HOMA-IR) in adolescent girls with obesity [83]. Further research examining the impact of circadian misalignment on IR is needed in other adolescent populations particularly given the increased risk for delayed circadian rhythm in this age group.

Evidence suggests that racial and ethnic background and sex may also be important to consider [84•]. In adults, racial disparities in cardiometabolic risk were explained in part by the shorter sleep duration and poorer sleep efficiency obtained by Black compared with White individuals [85]. Racial disparities in sleep have been documented with Black individuals demonstrating shorter sleep duration compared with White individuals $[86,87]$. The incidence rate of T2D is increasing at a faster rate for non-White youth, and racial differences in beta-cell responsiveness have been found in adolescents [3, 88]. To our knowledge, racial and ethnic differences have not been examined in the adolescent sleep and T2D literature but are important factors to consider for future study.

Sex differences are also an area in need of further exploration. Adolescent girls are at increased risk for insufficient sleep duration: compared with boys, adolescent girls report more daytime sleepiness, and a later chronotype $[89,90]$. Despite similar bedtimes, adolescent girls wake significantly earlier than boys on weekdays and shift their bed and wake times significantly later than boys on weekends $[90,91]$. Additionally, limited studies suggest sex differences with regards to glucose metabolism and exposure and influence of obesogenic factors $[92,93]$. However, findings regarding sex differences in sleep and T2D risk are unclear. In some studies, a relationship between sleep duration and BMI has been found for male but not female adolescents [94], while in others, insufficient sleep was associated with increased obesity risk for females but not males [95, 96]. Thus, further research to better understand these relationships is needed.

Finally, research on the unintended consequences of the COVID-19 pandemic on adolescent sleep in relation to T2D risk is important. Recent findings show that adolescents report longer sleep duration since the start of the pandemic and the shift to online learning [97], but it is unclear whether this equates to changes in risk for T2D. Additional data on sleep timing, physical activity, sedentary behaviors, and dietary habits during the COVID-19 time period are also needed.

\section{Conclusions}

Our model proposes that insufficient sleep in adolescence increases risk for T2D both directly through its impact on IR and indirectly through increased dietary intake, sedentary behavior, and weight gain. This is alarming given that a majority of adolescents are not achieving the recommended sleep duration, particularly on school nights [98-101]. Moreover, adolescents are already at increased risk for abnormal glucose metabolism as puberty is strongly associated with IR [6]. Health behaviors established during adolescence often persist into adulthood, making adolescence a critical window for intervention [102]. Adolescents self-direct their food choices more than younger children [103] and poor eating habits are prevalent in teens [104]. Rates of screen-time surge, while physical activity levels plummet during this high-risk developmental stage $[18,19]$. Thus, prioritizing sleep health promotion clinically and through public health changes such as delaying high school start times is urgently needed. Moreover, additional research in adolescents examining the impact of 
improving sleep health on insulin sensitivity and T2D risk factors is imperative.

Authors' Contributions SLS had the idea for the article, performed the literature search, and drafted the manuscript; JH, EM, KPW, and KJN helped develop the model and critically revised the work.

Funding Funding provided by SLS: K23DK117021, K12HD057022.

\section{Compliance with Ethical Standards}

Conflict of Interest Kenneth P. Wright Jr. reports during the conduct of the study being a consultant to/and/or receiving personal fees from Circadian Therapeutics, Inc., Circadian Biotherapies, Inc., Philips, Inc.; and receiving research support from the NIH, the Office of Naval Research, the PAC-12 Conference, and Somalogic, Inc., outside the submitted work. EM is supported by resources from the Geriatric Research, Education, and the Clinical Center at the Denver VA Medical Center. The contents do not represent the views of the U.S. Department of Veterans Affairs or the United States Government.

Stacey L. Simon, Janine Higgins, Edward Melanson, and Kristen J. Nadeau each declare no potential conflicts of interest.

Human and Animal Rights All reported studies/experiments with human or animal subjects performed by the authors have been previously published and complied with all applicable ethical standards (including the Helsinki declaration and its amendments, institutional/national research committee standards, and international/national/institutional guidelines).

\section{References}

Papers of particular interest, published recently, have been highlighted as:

- Of importance

•- Of major importance

1. Centers for Disease Control and Prevention. Youth Risk Behavior Survey Data. 2019. www.cdc.gov/yrbs.

2. Paruthi S, Brooks LJ, D'Ambrosio C, Hall WA, Kotagal S, Lloyd RM, et al. Recommended amount of sleep for pediatric populations: a consensus statement of the American Academy of Sleep Medicine. J Clin Sleep Med. 2016;12(6):785-6. https://doi.org/ 10.5664/jcsm.5866.

3. Mayer-Davis EJ, Lawrence JM, Dabelea D, Divers J, Isom S, Dolan L, et al. Incidence trends of type 1 and type 2 diabetes among youths, 2002-2012. N Engl J Med. 2017;376(15):141929. https://doi.org/10.1056/NEJMoa1610187.

4. Crowley SJ, Wolfson AR, Tarokh L, Carskadon MA. An update on adolescent sleep: new evidence informing the perfect storm model. J Adolesc. 2018;67:55-65. https://doi.org/10.1016/j. adolescence.2018.06.001.

5. Simon SL, Diniz Behn C, Cree-Green M, Kaar JL, Pyle L, Hawkins SMM, et al. Too late and not enough: school year sleep duration, timing, and circadian misalignment are associated with reduced insulin sensitivity in adolescents with overweight/obesity. J Pediatr. 2019;205:257-64.

6. Kelsey MM, Zeitler PS. Insulin resistance of puberty. Curr Diabetes Rep. 2016;16(7):64. https://doi.org/10.1007/s11892016-0751-5.
7. Cree-Green M, Triolo TM, Nadeau KJ. Etiology of insulin resistance in youth with type 2 diabetes. Curr Diabetes Rep. 2013;13(1):81-8. https://doi.org/10.1007/s11892-012-0341-0.

8. Zeitler P, Hirst K, Pyle L, Linder B, Copeland K, Arslanian S, et al. A clinical trial to maintain glycemic control in youth with type 2 diabetes. N Engl J Med. 2012;366(24):2247-56. https://doi. org/10.1056/NEJMoa1109333.

9. Hales CM, Fryar CD, Carroll MD, Freedman DS, Ogden CL. Trends in obesity and severe obesity prevalence in US youth and adults by sex and age, 2007-2008 to 2015-2016. Jama. 2018;319(16):1723-5. https://doi.org/10.1001/jama.2018.3060.

10. Wong PM, Manuck SB, DiNardo MM, Korytkowski M, Muldoon MF. Shorter sleep duration is associated with decreased insulin sensitivity in healthy white men. Sleep. 2015;38(2):223-31. https://doi.org/10.5665/sleep.4402.

11. Darukhanavala A, Booth JN 3rd, Bromley L, Whitmore H, Imperial J, Penev PD. Changes in insulin secretion and action in adults with familial risk for type 2 diabetes who curtail their sleep. Diabetes Care. 2011;34(10):2259-64. https://doi.org/10.2337/ dc11-0777.

12. Robertson MD, Russell-Jones D, Umpleby AM, Dijk DJ. Effects of three weeks of mild sleep restriction implemented in the home environment on multiple metabolic and endocrine markers in healthy young men. Metab Clin Exp. 2013;62(2):204-11. https://doi.org/10.1016/j.metabol.2012.07.016.

13. Buxton OM, Pavlova M, Reid EW, Wang W, Simonson DC, Adler GK. Sleep restriction for 1 week reduces insulin sensitivity in healthy men. Diabetes. 2010;59(9):2126-33. https://doi.org/10. 2337/db09-0699.

14. Broussard JL, Ehrmann DA, Van Cauter E, Tasali E, Brady MJ. Impaired insulin signaling in human adipocytes after experimental sleep restriction: a randomized, crossover study. Ann Intern Med. 2012;157(8):549-57. https://doi.org/10.7326/0003-4819-157-8201210160-00005.

15. Donga E, van Dijk M, van Dijk JG, Biermasz NR, Lammers GJ, van Kralingen $\mathrm{KW}$, et al. A single night of partial sleep deprivation induces insulin resistance in multiple metabolic pathways in healthy subjects. J Clin Endocrinol Metab. 2010;95(6):2963-8. https://doi.org/10.1210/jc.2009-2430.

16. Eckel RH, Depner CM, Perreault L, Markwald RR, Smith MR, McHill AW, et al. Morning circadian misalignment during short sleep duration impacts insulin sensitivity. Curr Biol. 2015;25: 3004-10. https://doi.org/10.1016/j.cub.2015.10.011.

17. Buysse DJ. Sleep health: can we define it? Does it matter? Sleep. 2014;37(1):9-17. https://doi.org/10.5665/sleep.3298.

18. Tashjian SM, Mullins JL, Galván A. Bedtime autonomy and cellphone use influence sleep duration in adolescents. J Adolesc Health. 2019;64(1):124-30. https://doi.org/10.1016/j.jadohealth. 2018.07.018.

19. Mireku MO, Barker MM, Mutz J, Dumontheil I, Thomas MSC, Röösli M, et al. Night-time screen-based media device use and adolescents' sleep and health-related quality of life. Environ Int. 2019;124:66-78. https://doi.org/10.1016/j.envint.2018.11.069.

20. Short MA, Weber N, Reynolds C, Coussens S, Carskadon MA. Estimating adolescent sleep need using dose-response modeling. Sleep. 2018;41(4). https://doi.org/10.1093/sleep/zsy011.

21. Fuligni AJ, Arruda EH, Krull JL, Gonzales NA. Adolescent sleep duration, variability, and peak levels of achievement and mental health. Child Dev. 2018;89(2):e18-28. https://doi.org/10.1111/ cdev.12729.

22. School start times for adolescents. Pediatrics. 2014;134(3):642-9. https://doi.org/10.1542/peds.2014-1697.

23. Cappuccio FP, Taggart FM, Kandala NB, Currie A, Peile E, Stranges S, et al. Meta-analysis of short sleep duration and obesity in children and adults. Sleep. 2008;31(5):619-26. 
24. Kracht CL, Chaput JP, Martin CK, Champagne CM, Katzmarzyk PT, Staiano AE. Associations of sleep with food cravings, diet, and obesity in adolescence. Nutrients. 2019;11(12). https://doi. org/10.3390/nu11122899 This study examined objectively measured sleep, physical activity, and diet and found that not meeting health behavior guidelines was associated with increased cardiometabolic risk.

25. Fatima Y, Doi SAR, Al MA. Sleep problems in adolescence and overweight/obesity in young adults: is there a causal link? Sleep Health. 2018;4(2):154-9. https://doi.org/10.1016/j.sleh.2018.01. 002 .

26. Ames ME, Holfeld B, Leadbeater BJ. Sex and age group differences in the associations between sleep duration and BMI from adolescence to young adulthood. Psychol Health. 2016;31:1-17. https://doi.org/10.1080/08870446.2016.1163360.

27. Miller MA, Kruisbrink M, Wallace J, Ji C, Cappuccio FP. Sleep duration and incidence of obesity in infants, children, and adolescents: a systematic review and meta-analysis of prospective studies. Sleep. 2018;41(4). https://doi.org/10.1093/sleep/zsy018 A recent analysis showing that insufficient sleep is a risk factor for obesity in youth across development.

28.• Reutrakul S, Van Cauter E. Sleep influences on obesity, insulin resistance, and risk of type 2 diabetes. Metab Clin Exp. 2018;84: 56-66. https://doi.org/10.1016/j.metabol.2018.02.010 A comprehensive review describing the effects of experimental sleep restriction on impaired glucose metabolism and diabetes risk, including a discussion of potential mechanisms.

29. Markwald RR, Melanson EL, Smith MR, Higgins J, Perreault L, Eckel RH, et al. Impact of insufficient sleep on total daily energy expenditure, food intake, and weight gain. Proc Natl Acad Sci U S A. 2013;110(14):5695-700. https://doi.org/10.1073/pnas. 1216951110.

30. Beebe DW, Simon S, Summer S, Hemmer S, Strotman D, Dolan LM. Dietary intake following experimentally restricted sleep in adolescents. Sleep. 2013;36(6):827-34. https://doi.org/10.5665/ sleep. 2704 .

31. Simon SL, Field J, Miller LE, DiFrancesco M, Beebe DW. Sweet/ dessert foods are more appealing to adolescents after sleep restriction. PLoS One. 2015;10(2):e0115434. https://doi.org/10.1371/ journal.pone.0115434.

32. Duraccio KM, Zaugg K, Jensen CD. Effects of sleep restriction on food-related inhibitory control and reward in adolescents. J Pediatr Psychol. 2019;44(6):692-702. https://doi.org/10.1093/jpepsy/ jsz008.

33. Felső R, Lohner S, Hollódy K, Erhardt É, Molnár D. Relationship between sleep duration and childhood obesity: systematic review including the potential underlying mechanisms. Nutr Metab Cardiovasc Dis. 2017;27(9):751-61. https://doi.org/10.1016/j. numecd.2017.07.008.

34. Broussard JL, Kilkus JM, Delebecque F, Abraham V, Day A, Whitmore HR, et al. Elevated ghrelin predicts food intake during experimental sleep restriction. Obesity (Silver Spring, Md). 2016;24(1):132-8. https://doi.org/10.1002/oby.21321.

35. Lin J, Jiang Y, Wang G, Meng M, Zhu Q, Mei H, et al. Associations of short sleep duration with appetite-regulating hormones and adipokines: a systematic review and meta-analysis. Obes Rev. 2020;21:e13051. https://doi.org/10.1111/obr.13051.

36. Hart CN, Carskadon MA, Considine RV, Fava JL, Lawton J, Raynor HA, et al. Changes in children's sleep duration on food intake, weight, and leptin. Pediatrics. 2013;132(6):e1473-80. https://doi.org/10.1542/peds.2013-1274.

37. Klingenberg L, Chaput JP, Holmbäck U, Jennum P, Astrup A, Sjödin A. Sleep restriction is not associated with a positive energy balance in adolescent boys. Am J Clin Nutr. 2012;96(2):240-8. https://doi.org/10.3945/ajen.112.038638.
38. Baron KG, Reid KJ, Horn LV, Zee PC. Contribution of evening macronutrient intake to total caloric intake and body mass index. Appetite. 2013;60(1):246-51. https://doi.org/10.1016/j.appet. 2012.09.026.

39. McHill AW, Phillips AJ, Czeisler CA, Keating L, Yee K, Barger LK, et al. Later circadian timing of food intake is associated with increased body fat. Am J Clin Nutr. 2017;106(5):1213-9. https:// doi.org/10.3945/ajen.117.161588.

40. Stothard ER, Ritchie HK, Birks BR, Eckel RH, Higgins J, Melanson EL, et al. Early morning food intake as a risk factor for metabolic dysregulation. Nutrients. 2020;12(3). https://doi. org/10.3390/nu12030756.

41. Mathias KC, Almoosawi S, Karagounis LG. Protein and energy intakes are skewed toward the evening among children and adolescents in the United States: NHANES 2013-2014. J Nutr. 2017;147(6):1160-6. https://doi.org/10.3945/jn.116.245621.

42. Rossbach S, Diederichs T, Nothlings U, Buyken AE, Alexy U. Relevance of chronotype for eating patterns in adolescents. Chronobiol Int. 2017;35:1-12. https://doi.org/10.1080/ 07420528.2017 .1406493

43. Grummon AH, Sokol RL, Lytle LA. Is late bedtime an overlooked sleep behaviour? Investigating associations between sleep timing, sleep duration and eating behaviours in adolescence and adulthood. Public Health Nutr. 2020:1-7. https://doi.org/10.1017/ s1368980020002050.

44. Al-Hazzaa HM, Musaiger AO, Abahussain NA, Al-Sobayel HI, Qahwaji DM. Lifestyle correlates of self-reported sleep duration among Saudi adolescents: a multicentre school-based cross-sectional study. Child Care Health Dev. 2014;40(4):533-42. https:// doi.org/10.1111/cch.12051

45. Gába A, Dygrýn J, Štefelová N, Rubín L, Hron K, Jakubec L, et al. How do short sleepers use extra waking hours? A compositional analysis of 24-h time-use patterns among children and adolescents. Int J Behav Nutr Phys Act. 2020;17(1):104. https://doi. org/10.1186/s12966-020-01004-8.

46. Hayes JF, Balantekin KN, Altman M, Wilfley DE, Taylor CB, Williams J. Sleep patterns and quality are associated with severity of obesity and weight-related behaviors in adolescents with overweight and obesity. Childhood Obesity (Print). 2018;14(1):11-7. https://doi.org/10.1089/chi.2017.0148.

47. Stea TH, Knutsen T, Torstveit MK. Association between short time in bed, health-risk behaviors and poor academic achievement among Norwegian adolescents. Sleep Med. 2014;15(6):666-71. https://doi.org/10.1016/j.sleep.2014.01.019.

48. Gong QH, Li H, Zhang XH, Zhang T, Cui J, Xu GZ. Associations between sleep duration and physical activity and dietary behaviors in Chinese adolescents: results from the Youth Behavioral Risk Factor Surveys of 2015. Sleep Med. 2017;37:168-73. https://doi. org/10.1016/j.sleep.2017.06.024.

49. Luo J, Cao M, Sun F, Shi B, Wang X, Jing J. Association between outdoor activity and insufficient sleep in Chinese school-aged children. Med Sci Monit. 2020;26:e921617. https://doi.org/10. 12659/msm.921617.

50. Van Dyk TR, Krietsch KN, Saelens BE, Whitacre C, McAlister S, Beebe DW. Inducing more sleep on school nights reduces sedentary behavior without affecting physical activity in short-sleeping adolescents. Sleep Med. 2018;47:7-10. https://doi.org/10.1016/j. sleep.2018.03.007.

51. Kracht CL, Champagne CM, Hsia DS, Martin CK, Newton RL Jr, Katzmarzyk PT, et al. Association between meeting physical activity, sleep, and dietary guidelines and cardiometabolic risk factors and adiposity in adolescents. J Adolesc Health. 2020;66(6): 733-9. https://doi.org/10.1016/j.jadohealth.2019.12.011.

52. Saunders TJ, Gray CE, Poitras VJ, Chaput JP, Janssen I, Katzmarzyk PT, et al. Combinations of physical activity, sedentary behaviour and sleep: relationships with health indicators in 
school-aged children and youth. Appl Physiol Nutri Metabol. 2016;41(6 Suppl 3):S283-93. https://doi.org/10.1139/apnm2015-0626.

53. De Bernardi Rodrigues AM, da Silva CC, Vasques AC, Camilo DF, Barreiro F, Cassani RS, et al. Association of sleep deprivation with reduction in insulin sensitivity as assessed by the hyperglycemic clamp technique in adolescents. JAMA Pediatr. 2016;170(5):487-94. https://doi.org/10.1001/jamapediatrics. 2015.4365

54. Matthews KA, Dahl RE, Owens JF, Lee L, Hall M. Sleep duration and insulin resistance in healthy black and white adolescents. Sleep. 2012;35(10):1353-8. https://doi.org/10.5665/sleep.2112.

55. Javaheri S, Storfer-Isser A, Rosen CL, Redline S. Association of short and long sleep durations with insulin sensitivity in adolescents. J Pediatr. 2011;158(4):617-23. https://doi.org/10.1016/j. jpeds.2010.09.080.

56. Thumann BF, Michels N, Felső R, Hunsberger M, Kaprio J, Moreno LA, et al. Associations between sleep duration and insulin resistance in European children and adolescents considering the mediating role of abdominal obesity. PLoS One. 2020;15(6): e0235049. https://doi.org/10.1371/journal.pone.0235049.

57. Cespedes Feliciano EM, Quante M, Rifas-Shiman SL, Redline S, Oken E, Taveras EM. Objective sleep characteristics and cardiometabolic health in young adolescents. Pediatrics. 2018;142(1). https://doi.org/10.1542/peds.2017-4085 This study of over 800 adolescents found that better objectively-measured sleep health (duration and efficiency) was associated with lower metabolic risk.

58. Klingenberg L, Chaput JP, Holmback U, Visby T, Jennum P, Nikolic M, et al. Acute sleep restriction reduces insulin sensitivity in adolescent boys. Sleep. 2013;36(7):1085-90. https://doi.org/10. 5665/sleep.2816.

59. Yadav D, Cho KH. Total sleep duration and risk of type 2 diabetes: evidence-based on clinical and epidemiological studies. Curr Drug Metab. 2018;19(12):979-85. https://doi.org/10.2174/ 1389200219666180628170431 This review confirmed a Ushaped relationship between short and long sleep duration with type 2 diabetes risk in adults.

60. Shan Z, Ma H, Xie M, Yan P, Guo Y, Bao W, et al. Sleep duration and risk of type 2 diabetes: a meta-analysis of prospective studies. Diabetes Care. 2015;38(3):529-37. https://doi.org/10.2337/dc142073.

61. Anothaisintawee T, Reutrakul S, Van Cauter E, Thakkinstian A. Sleep disturbances compared to traditional risk factors for diabetes development: systematic review and meta-analysis. Sleep Med Rev. 2016;30:11-24. https://doi.org/10.1016/j.smrv.2015.10.002.

62. Dutil C, Chaput JP. Inadequate sleep as a contributor to type 2 diabetes in children and adolescents. Nutr Diabetes. 2017;7(5): e266. https://doi.org/10.1038/nutd.2017.19.

63.• Widome R, Berger AT, Iber C, Wahlstrom K, Laska MN, Kilian $\mathrm{G}$, et al. Association of delaying school start time with sleep duration, timing, and quality among adolescents. JAMA Pediatr. 2020;174(7):1-9. https://doi.org/10.1001/jamapediatrics.2020. 0344 An observational cohort study followed adolescents from $9^{\text {th }}$ to $11^{\text {th }}$ grade in schools that either delayed or maintained their school start times. Objectively measured sleep duration increased sleep duration on school nights for students with delayed school start times, suggesting this is a feasible approach to increase adolescent sleep duration.

64. Dunster GP, de la Iglesia L, Ben-Hamo M, Nave C, Fleischer JG, Panda S, et al. Sleepmore in Seattle: later school start times are associated with more sleep and better performance in high school students. Sci Adv. 2018;4(12):eaau6200. https://doi.org/10.1126/ sciadv.aau6200.

65. Killick R, Hoyos CM, Melehan KL, Dungan GC 2nd, Poh J, Liu PY. Metabolic and hormonal effects of 'catch-up' sleep in men with chronic, repetitive, lifestyle-driven sleep restriction. Clin Endocrinol. 2015;83(4):498-507. https://doi.org/10.1111/cen. 12747.

66. Broussard JL, Wroblewski K, Kilkus JM, Tasali E. Two nights of recovery sleep reverses the effects of short-term sleep restriction on diabetes risk. Diabetes Care. 2016;39(3):e40-1. https://doi.org/ $10.2337 / \mathrm{dc} 15-2214$.

67. Depner CM, Melanson EL, Eckel RH, Snell-Bergeon JK, Perreault L, Bergman BC, et al. Ad libitum weekend recovery sleep fails to prevent metabolic dysregulation during a repeating pattern of insufficient sleep and weekend recovery sleep. Curr Biol. 2019;29(6):957-67.e4. https://doi.org/10.1016/j.cub.2019. 01.069 .

68. Ness KM, Strayer SM, Nahmod NG, Chang AM, Buxton OM, Shearer GC. Two nights of recovery sleep restores the dynamic lipemic response, but not the reduction of insulin sensitivity, induced by five nights of sleep restriction. Am J Phys Regul Integr Comp Phys. 2019;316(6):R697-r703. https://doi.org/10.1152/ ajpregu.00336.2018.

69. Leproult R, Deliens G, Gilson M, Peigneux P. Beneficial impact of sleep extension on fasting insulin sensitivity in adults with habitual sleep restriction. Sleep. 2015;38(5):707-15. https://doi. org/10.5665/sleep.4660.

70. Beebe DW, Fallone G, Godiwala N, Flanigan M, Martin D, Schaffner L, et al. Feasibility and behavioral effects of an athome multi-night sleep restriction protocol for adolescents. J Child Psychol Psychiatry Allied Discip. 2008;49(9):915-23. https://doi.org/10.1111/j.1469-7610.2008.01885.x.

71. Van Dyk TR, Zhang N, Catlin PA, Cornist K, McAlister S, Whitacre $\mathrm{C}$, et al. Feasibility and emotional impact of experimentally extending sleep in short-sleeping adolescents. Sleep. 2017;40(9). https://doi.org/10.1093/sleep/zsx123.

72. Dewald-Kaufmann JF, Oort FJ, Meijer AM. The effects of sleep extension on sleep and cognitive performance in adolescents with chronic sleep reduction: an experimental study. Sleep Med. 2013;14(6):510-7. https://doi.org/10.1016/j.sleep.2013.01.012.

73. Gruber R, Cassoff J, Frenette S, Wiebe S, Carrier J. Impact of sleep extension and restriction on children's emotional lability and impulsivity. Pediatrics. 2012;130(5):e1155-61. https://doi. org/10.1542/peds.2012-0564.

74. de Zwart BJ, Beulens JWJ, Elders P, Rutters F. Pilot data on the association between social jetlag and obesity-related characteristics in Dutch adolescents over one year. Sleep Med. 2018;47:325. https://doi.org/10.1016/j.sleep.2018.03.024.

75. Wong PM, Hasler BP, Kamarck TW, Muldoon MF, Manuck SB. Social jetlag, chronotype, and cardiometabolic risk. J Clin Endocrinol Metab. 2015;100(12):4612-20. https://doi.org/10. 1210/jc.2015-2923.

76. Koopman ADM, Rauh SP, van 't Riet E, Groeneveld L, van der Heijden AA, Elders PJ, et al. The association between social jetlag, the metabolic syndrome, and type 2 diabetes mellitus in the general population: the New Hoorn Study. J Biol Rhythm. 2017;32(4):359-68. https://doi.org/10.1177/0748730417713572.

77. Cespedes Feliciano EM, Rifas-Shiman SL, Quante M, Redline S, Oken E, Taveras EM. Chronotype, social jet lag, and cardiometabolic risk factors in early adolescence. JAMA Pediatr. 2019;173(11):1049-57. https://doi.org/10.1001/jamapediatrics. 2019.3089 .

78. Mathew GM, Hale L, Chang AM. Social jetlag, eating behaviours and BMI among adolescents in the USA. Br J Nutr. 2020;124(9): 979-87. https://doi.org/10.1017/s0007114520001804.

79. Johnson DA, Reid M, Vu TT, Gallo LC, Daviglus ML, Isasi CR, et al. Associations of sleep duration and social jetlag with cardiometabolic risk factors in the study of Latino youth. Sleep Health. 2020;6:563-9. https://doi.org/10.1016/j.sleh.2020.02.017. 
80. Wright KP Jr, McHill AW, Birks BR, Griffin BR, Rusterholz T, Chinoy ED. Entrainment of the human circadian clock to the natural light-dark cycle. Curr Biol. 2013;23(16):1554-8. https://doi. org/10.1016/j.cub.2013.06.039.

81. Leproult R, Holmback U. Circadian misalignment augments markers of insulin resistance and inflammation, independently of sleep loss. 2014;63(6):1860-9. https://doi.org/10.2337/db131546.

82. Crowley SJ, Van Reen E, LeBourgeois MK, Acebo C, Tarokh L, Seifer R, et al. A longitudinal assessment of sleep timing, circadian phase, and phase angle of entrainment across human adolescence. PLoS One. 2014;9(11):e112199. https://doi.org/10.1371/journal. pone. 0112199 .

83. Simon SL, McWhirter L, Diniz Behn C, Bubar KM, Kaar JL, Pyle $\mathrm{L}$, et al. Morning circadian misalignment is associated with insulin resistance in girls with obesity and polycystic ovarian syndrome. J Clin Endocrinol Metab. 2019;104(8):3525-34. https://doi.org/10. 1210/jc.2018-02385.

86. Koren D, Taveras EM, et al. Metab Clin Exp. 2018;84:67-75. https://doi.org/10.1016/j.metabol.2018.04.001 A review article summarizing recent evidence associating insufficient sleep with risk for type 2 diabetes across the lifespan.

85. Curtis DS, Fuller-Rowell TE, El-Sheikh M, Carnethon MR, Ryff CD. Habitual sleep as a contributor to racial differences in cardiometabolic risk. Proc Natl Acad Sci U S A. 2017;114(33):8889-94. https://doi.org/10.1073/pnas.1618167114.

86. Petrov ME, Lichstein KL. Differences in sleep between black and white adults: an update and future directions. Sleep Med. 2016;18: 74-81. https://doi.org/10.1016/j.sleep.2015.01.011.

87. Matthews KA, Hall M, Dahl RE. Sleep in healthy black and white adolescents. Pediatrics. 2014;133(5):e1189-96. https://doi.org/10. 1542/peds.2013-2399.

88. Bacha F, Gungor N, Lee S, Arslanian SA. Type 2 diabetes in youth: are there racial differences in $\beta$-cell responsiveness relative to insulin sensitivity? Pediatr Diabetes. 2012;13(3):259-65. https://doi.org/10.1111/j.1399-5448.2011.00820.x.

89. Spilsbury JC, Drotar D, Rosen CL, Redline S. The Cleveland adolescent sleepiness questionnaire: a new measure to assess excessive daytime sleepiness in adolescents. J Clin Sleep Med. 2007;3(6):603-12.

90. Collado Mateo MJ, Diaz-Morales JF, Escribano Barreno C, Delgado Prieto P, Randler C. Morningness-eveningness and sleep habits among adolescents: age and gender differences. Psicothema. 2012;24(3):410-5.

91. Lee KA, McEnany G, Weekes D. Gender differences in sleep patterns for early adolescents. J Adolesc Health. 1999;24(1):1620.

92. Perreault L, Ma Y, Dagogo-Jack S, Horton E, Marrero D, Crandall $\mathrm{J}$, et al. Sex differences in diabetes risk and the effect of intensive lifestyle modification in the diabetes prevention program.
Diabetes Care. 2008;31(7):1416-21. https://doi.org/10.2337/ dc07-2390.

93. Sweeting HN. Gendered dimensions of obesity in childhood and adolescence. Nutr J. 2008;7:1. https://doi.org/10.1186/1475-2891$7-1$.

94. Chen X, Beydoun MA, Wang Y. Is sleep duration associated with childhood obesity? A systematic review and meta-analysis. Obesity (Silver Spring, Md). 2008;16(2):265-74. https://doi.org/ 10.1038/oby.2007.63.

95. Suglia SF, Kara S, Robinson WR. Sleep duration and obesity among adolescents transitioning to adulthood: do results differ by sex? J Pediatr. 2014;165(4):750-4. https://doi.org/10.1016/j. jpeds.2014.06.052.

96. Lowry R, Eaton DK, Foti K, McKnight-Eily L, Perry G, Galuska DA. Association of sleep duration with obesity among US high school students. J Obes. 2012;2012:476914-9. https://doi.org/10. 1155/2012/476914.

97. Twenge, JM, Coyne SM, Carroll JS, Wilcox WB. Teens in quarantine: mental health, screen time, and family connection. Institute for Family Studies: The Wheatley Institution. 2020. https:// ifstudies.org/ifs-admin/resources/final-teenquarantine2020.pdf.

98. Smaldone A, Honig JC, Byrne MW. Sleepless in America: inadequate sleep and relationships to health and well-being of our nation's children. Pediatrics. 2007;119(Suppl 1):S29-37. https:// doi.org/10.1542/peds.2006-2089F.

99. National Sleep Foundation. Sleep in America Poll: teens and sleep. Washington, DC: National Sleep Foundation; 2006.

100. Bartel KA, Gradisar M, Williamson P. Protective and risk factors for adolescent sleep: a meta-analytic review. Sleep Med Rev. 2015;21:72-85. https://doi.org/10.1016/j.smrv.2014.08.002.

101. Wheaton AG, Jones SE, Cooper AC, Croft JB. Short sleep duration among middle school and high school students - United States, 2015. MMWR Morb Mortal Wkly Rep. 2018;67(3):8590. https://doi.org/10.15585/mmwr.mm6703a1.

102. Guidelines for school health programs to promote lifelong healthy eating. Centers for Disease Control and Prevention. MMWR Recommendations and reports : Morbidity and mortality weekly report Recommendations and reports / Centers for Disease Control. 1996;45(Rr-9):1-41.

103. Videon TM, Manning CK. Influences on adolescent eating patterns: the importance of family meals. J Adolesc Health. 2003;32(5):365-73.

104. Wiium N, Breivik K, Wold B. Growth trajectories of health behaviors from adolescence through young adulthood. Int J Environ Res Public Health 2015;12(11):13711-29. https://doi.org/10. 3390/ijerph121113711.

Publisher's Note Springer Nature remains neutral with regard to jurisdictional claims in published maps and institutional affiliations. 